DIW BERLIN

Discussion

Papers

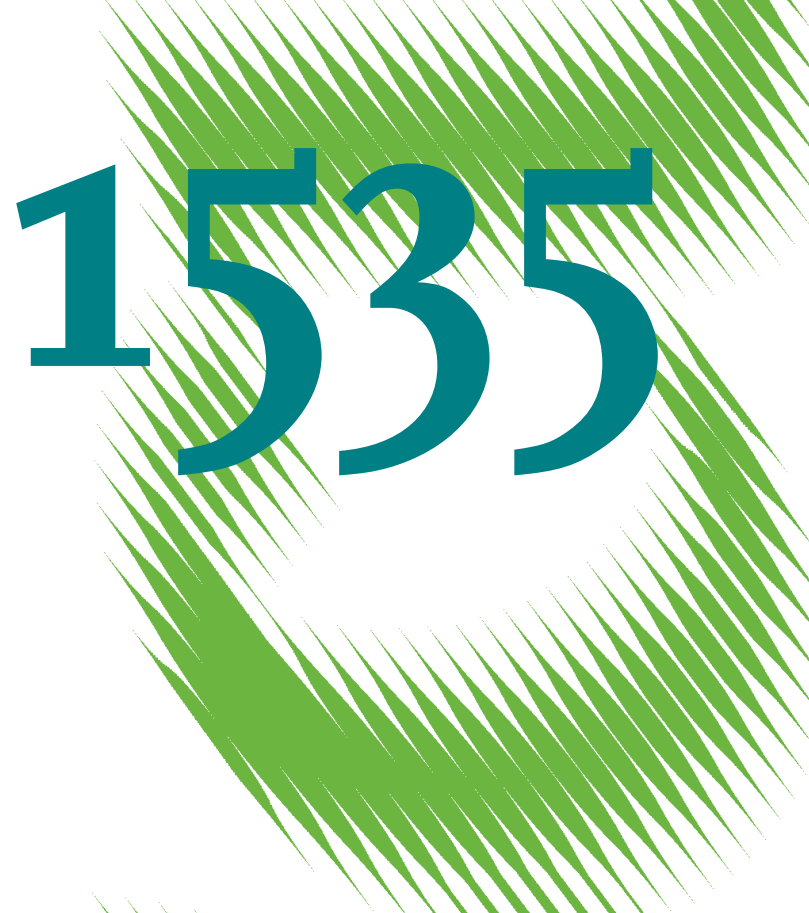

Crowding in Public Transport: Who Cares and Why? 
Opinions expressed in this paper are those of the author(s) and do not necessarily reflect views of the institute.

IMPRESSUM

(C) DIW Berlin, 2015

DIW Berlin

German Institute for Economic Research

Mohrenstr. 58

10117 Berlin

Tel. +49 (30) $89789-0$

Fax +49 (30) $89789-200$

http://www.diw.de

ISSN electronic edition 1619-4535

Papers can be downloaded free of charge from the DIW Berlin website:

http://www.diw.de/discussionpapers

Discussion Papers of DIW Berlin are indexed in RePEc and SSRN:

http://ideas.repec.org/s/diw/diwwpp.html

http://www.ssrn.com/link/DIW-Berlin-German-Inst-Econ-Res.html 


\title{
Crowding in public transport: who cares and why?
}

\author{
Luke Haywood $^{1}$, Martin Koning ${ }^{2}$, and Guillaume Monchambert*3 \\ ${ }^{1}$ DIW Berlin, Germany \\ ${ }^{2}$ Paris East University, France, and IFSTTAR, France \\ ${ }^{3}$ KULeuven, Belgium, and ENS Cachan, France
}

December 15, 2015

\begin{abstract}
Crowding on public transport (PT) is a major issue for commuters around the world. Nevertheless, economists have rarely investigated the causes of crowding discomfort. Furthermore, most evidence on the costs of PT crowding is based on contingent valuation studies. First, this paper assesses discomfort with PT crowding over different density levels, trip durations and across different individuals using a different methodology. Based on a survey of 1,000 Paris PT users, the negative, linear relationship of in-vehicle density on reported travel satisfaction is remarkably similar to previous studies investigating PT crowding costs and stable across most individual characteristics. Contrary to the identifying assumption of most contingent valuation studies, we find little increase in crowding costs over travel time, in line with an additive specification of the generalized PT cost function. Second, we investigate the causes of this discomfort effect. We identify three key drivers: (a) dissatisfaction with standing and not being seated; (b) less opportunities to make use of the time during the journey; (c) the physical closeness of other travellers per se.
\end{abstract}

Keywords: public transport; crowding; stated satisfaction; travel cost; survey data

JEL: D01; C25; R41

${ }^{*}$ Corresponding author. E-mail: guillaume.monchambert @kuleuven.be 


\section{Introduction}

Among the relevant qualitative attributes of PT, availability of space in vehicles is often singled out as one of the most desirable dimension (Eboli and Mazzulla, 2007; Dell'Olio et al., 2011). Many cities have attempted to reduce individual motorized traffic. Given the low elasticity of PT supply, these policies have often coincided with less comfortable travel conditions. Theoretical models thus increase the cost of time in crowded PT - either discretely once users have to stand (Kraus, 1991), continuously with in-vehicle density (IVD) (Jara-Díaz and Gschwender, 2003), or a mix of both (de Palma et al., 2015). Significant welfare costs of crowded public transport are also found empirically (Wardman and Whelan, 2011; Haywood and Koning, 2015). Crowding is not only important for workers' welfare and their choices about working times (Tirachini et al., 2013), but also for firms scheduling working hours (Henderson, 1981). As a result, crowding in PT has been included in analyses of optimal public transport supply and pricing (De Borger and Wouters, 1998; Parry and Small, 2009).

Whilst higher IVD implies spatial limitation for individuals, it only generates economic consequences as an "experimental state" (see Stokols, 1972). Personal and trip characteristics may modify this experience, hence we take these into account in our analysis. Furthermore, this experience being intrinsically subjective ${ }^{1}$, it seems most relevant to use a subjective indicator to measure it. We use a self-reported satisfaction measure in this paper. Individuals are able to rate their well-being during long or short periods of time (Van Praag and Ferrer-i Carbonell, 2008). Metcalfe and Dolan (2012) conclude that reported satisfaction measure is a good measure of the underlying utility of a transport journey. Cantwell et al. (2009) decompose satisfaction for PT into three elements crowding, travel time reliability and monetary cost - and test their relative importance using an on-line survey on commuting in Dublin.

This paper focuses on comfort satisfaction (CS), allowing travel time to moderate CS alongside other trip and individual characteristics. The crowding effect is understood as the utility cost due

\footnotetext{
${ }^{1}$ Mohd Mahudin et al. (2012) distinguish three components of the experience of passenger crowding (evaluation of psychosocial aspects of the crowded situation, emotional reactions to the crowded situation and evaluation of the ambient environment of the crowded situation) to evaluate the relationship between crowding and stress and feelings of exhaustion.
} 
to lack of in-vehicle space and may thus vary across PT users: apart from IVD, it may also depend on travel and individual characteristics. In this framework, we address two research questions:

1. How does IVD relate to subjective CS stated by users and how does this crowding effect depend on travel time? We use data on individual self-reported measures of satisfaction (derived from a field survey conducted late 2010 on platforms of Paris subways). This data allows a direct assessment of the perception of crowding and its impact on the satisfaction of PT users is in line with the empirical literature on subjective well-being (Kahneman and Krueger, 2006) or job satisfaction (Clark and Senik, 2010) and contrasts with the transport literature which has mostly focused on contingent valuation studies. These latter studies generally rely on hypothetical trade-offs between travel time and density (see Wardman and Whelan, 2011 and Li and Hensher, 2011). These are then used to calculate "time multipliers" and integrate in-vehicle crowding as part of the generalized cost of PT via an increase in the benchmark value of travel time savings. Our alternative approach allows us to identify a crowding effect independent of travel time, which is not feasible in most contingent valuation studies. This strategy enables us to shed some light on the proper specification of the PT generalized cost function. Recent empirical evidence (Kroes et al., 2013) thus suggests that the crowding effect is independent of travel time.

2. What explains the discomfort associated with crowding in PT? We investigate the reasons for low CS, defined as "causes of crowding discomfort" (CCD), i.e. those features of a journey that are deteriorated by high passenger $I V D^{2}$. To our knowledge, we are the first to empirically test different candidate CCDs to understand the origins of the deterioration in CS. Having a better idea of the nuisances that really affect users can inform public policies. This study could thus highlight whether individuals will be better-off if they are offered additional seats, efficient cooling systems or more security in carriages.

The paper proceeds as follows. Section "2" presents the data and survey design. The Paris PT network constitutes a perfect case study to address in-vehicle crowding due to the recent growth in

\footnotetext{
${ }^{2}$ In this study, we consider eight causes of discomfort, described in detail in Section "2.2".
} 
its patronage and no evidence of bottleneck effets ${ }^{3}$. Section " 3 " estimates the relationship between crowding (IVD), satisfaction with PT (CS) and travel duration and contrasts our findings to studies based contingent valuation. Section "4" uses original data to assess the most important reasons for this crowding effect.

\section{Data}

Our data was collected in the Parisian mass transit network in late 2010. Around 1,000 users were interviewed directly on platforms of subway lines 1 and $4^{4}$, during morning (7:30-10am) and evening (5-7:30pm) peaks, whilst waiting for their train to arrive. Subway line 1 crosses Paris East-West. It is the busiest service of the subway network with 750,000 daily users in 2010, serving Europe's largest central business district La Défense and large tourist attractions. Subway line 4 crosses Paris North-South and is the second most used service of the network, with 670,000 daily travelers in 2010. It connects three long-distance train stations: Gare du Nord, Gare de Lyon and Gare Montparnasse. Users of lines 1 and 4 are very heterogeneous since the lines cover both wealthy and poor neighborhoods. This heterogeneity is useful to assess different individuals' preferences concerning PT crowding.

To elicit assessments of CS, PT users were shown a show-card (see Figure 1) and asked "Which density of users do you expect to face during your immediate journey?". The density levels on the show-card correspond to $0,1,2,2.5,3,4$ and 6 passengers per square meter respectively. We use this as a measure of IVD ${ }^{5}$. CS is assessed by answers to the question: "Given this density, mark your satisfaction associated with the comfort for your immediate journey on a scale from 0 to 10.", where 0 corresponds to highly dissatisfied and 10 to highly satisfied. To determine the factors causing discomfort in high-density PT, interviewers showed interviewees the most crowded situation on the

\footnotetext{
${ }^{3}$ An active anti-car policy has been there implemented and succeeded to enhance a huge modal shift toward rail-based PT. Since PT supply could not adapt as fast as PT demand, however, IVD grew by $10 \%$ over $2000-2009$ whilst service regularity remained unchanged, see Haywood and Koning (2015).

${ }^{4}$ The stations where the survey has been conducted are, from East to West, Gare de Lyon, Hôtel de Ville, Champs Elysées, Georges V, Argentine and Esplanade for line 1, and, from South to North, Denfert-Rochereau, Montparnasse-Bienvenüe, Saint Sulpice, Odéon and Les Halles for line 4.

${ }^{5}$ We collected an independent objective measure of density in carriages on the same lines, between the same stations at the relevant time periods. All results are robust to using this objective measure in the analysis.
} 


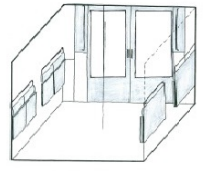

Carte 1

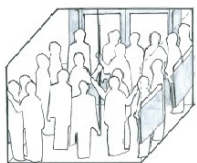

Carte 5

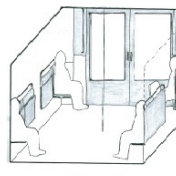

Carte 2

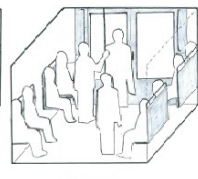

Carte 3

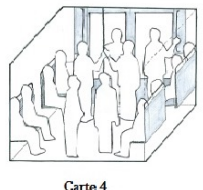

Carte 4

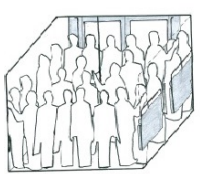

Carte 6

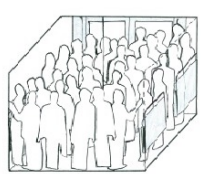

Carte 7

Figure 1: Density show-card used during the field survey

show-card ( 6 passengers per square meter) and asked them: "On a scale from 0 to 10 , mark the inconvenience associated with the following aspects when traveling in conditions similar to the ones represented on show-card : Over-closeness, Standing, Noise, Smell, Time loss, Waste of time, Fall and Robbery." The scale ranges from 0 (not concerned by this type of discomfort) to 10 (highly relevant cause of nuisance). Section "4" considers which of these causes of crowding discomfort (CCD) are the key features that are deteriorated by high IVD.

\subsection{Descriptive statistics}

Equal numbers of respondents were interviewed on lines 1 and 4, and during morning and evening peaks, with almost equal proportions of men (48\%) and women (52\%). We observe large socioeconomic heterogeneity, e.g. in income and age. A majority of the population is from central Paris (53\%). $37 \%$ of respondents own a car, representative of the Parisian population. Door-to-door travel time is 49 minutes, with on average 10 minutes on lines 1 or 4 . A large majority of the sample commute (71\%) and use lines 1 or 4 every day (64\%). Section "4" is based on a sub-sample of 278 individuals $^{6}$. The main difference between the two samples concerns the time of interview:

\footnotetext{
${ }^{6}$ All respondents provide information on IVD and CS necessary for the analysis in Section "3". Interviewees were then given the option of answering additional questions (used in Section " 4 "). This usually required taking a later train, given high service frequency at peak times.
} 
Table 1: Distribution of the in-vehicle density, IVD

\begin{tabular}{cc}
\hline \hline In vehicle density $\left(\right.$ pass $\left./ \mathrm{m}^{2}\right)$ & Frequencies $(\%)$ \\
\hline 0 & 0.1 \\
1 & 2.8 \\
2 & 16.2 \\
2.5 & 26.4 \\
3 & 24.2 \\
4 & 20.0 \\
6 & 10.2 \\
\hline \hline
\end{tabular}

$36 \%$ of sub-sample users travel during morning peaks (as opposed to $50 \%$ of the whole sample) ${ }^{7}$. They are also more likely to be commuters and use line 1 . The characteristics of the trip differ between the sub-sample and the rest of the sample, but the individual characteristics do not vary significantly. The samples are systematically compared to each other and differences tested for significance in Table (7) in Appendix "A".

Table (1) gives the distribution of surveyed IVD. Few individuals will have a seat in their trip: only 1 interviewee chose the "empty subway" situation and $2.8 \%$ chose the card with 1 passenger per square meter. By contrast, more than $10 \%$ indicate more than 6 passengers per square meter during their journey. More than $50 \%$ of the PT users think they will travel with 2.5-3 passengers per square meter around them with an average estimated density of 3.2 passengers per square meter. This distribution is very similar in the sub-sample.

Table (2) shows that CS is negatively related to the level of passenger density IVD. By contrast, we do not observe any clear relationship between CS and trip duration. Note that a lack of relation between travel time and users' crowding costs is contrary to the modeling of crowding costs as a multiplicative factor in trip duration (the most common representation in the literature, see Wardman and Whelan, 2011 and Jara-Díaz and Gschwender, 2003).

\footnotetext{
${ }^{7}$ This is consistent with the existence of scheduling costs that are more important in the morning (Small and Verhoef, 2007) and that may occur if individuals would answer to the longer survey (because deviating from their preferred arrival time).
} 
Table 2: Distribution of the comfort satisfaction, CS

\begin{tabular}{cccc}
\hline \hline CS & Frequency (\%) & Ave. IVD & Ave. IVTT \\
\hline 0 & 6.3 & 5.1 & 9.8 \\
1 & 4.3 & 4.3 & 9.7 \\
2 & 9.5 & 4.0 & 10.2 \\
3 & 11.4 & 3.4 & 10.1 \\
4 & 12.6 & 3.0 & 10.1 \\
5 & 21.9 & 2.8 & 9.8 \\
6 & 17.5 & 2.7 & 9.3 \\
7 & 10.4 & 2.6 & 8.8 \\
8 & 4.3 & 2.5 & 9.3 \\
9 & 1.2 & 2.0 & 11.1 \\
10 & 0.6 & 2.6 & 7.9 \\
\hline \hline
\end{tabular}

Notes. This table reports descriptive statistics for sub-samples clustered by CS. Column (2) reports the part of each sub-sample into the whole sample. Columns (3) and (4) respectively report the average IVD, in users per square meter, and the average in-vehicle travel time, in minutes, in each sub-sample.

\subsection{Dimensions of crowding discomfort}

Whilst some studies equate the discomfort of crowding with a lack of seating (e.g. Kraus, 1991), we distinguish eight dimensions of CS which may be affected by high IVD and about which individuals were questioned:

- Over-closeness: Crowding generates an intrusion in users' individual space. Passengers suffer from stress and lack of control (Epstein, 1981, and for PT in particular, Epstein et al., 1981).

- Standing: When passenger density on a train is high, users find no seat. This may lead to pain and discomfort (Boussenna et al., 1982).

- Noise may cause discomfort and mental health problems (Bhattacharya et al., 1995).

- Bad Smell increase with many passengers, not least as average temperatures increase with IVD.

- Time Loss: Crowding may increase dwell times at stations due to slower boarding and alighting. Furthermore, incidents on other points in the network may cause more delays, reducing reliability. 
- Waste of Time: When passenger density is high, users are not able to perform tasks they would like during their PT journeys, such as read a newspaper or work (Langrehr, 1991) ${ }^{8}$.

- Fall: In crowded situations, the risk of falling may increase.

- Robbery: Uzzell and Brown (2007) find higher rates of pick-pocketing in more crowded contexts.

Table (3) presents respondents ratings for each of these CCDs and categorizes them as psychological, physical, sensory, temporal and risky ${ }^{9}$. Since a rating of 1 for one particular CCD may not have the same meaning if all other dimensions are also rated 1 or if the others are rated 10 , we also include information on individuals' ranking of CCDs (we later include the sum of CCD ratings in our regressions for the same reason). The mean rankings and CCD scores are fairly similar: Over-closeness appears as the most relevant CCD. More than half of respondents rank this feature as the most unpleasant. Second and third are Smell and Standing. Robbery, Wasted Time, Noise and Time Loss are moderately rated causes of crowding discomfort. Lastly, risks of Fall due to high density are viewed as negligible by subway users.

\section{The crowding effect}

Many studies have documented a crowding effect, i.e. a link between IVD and generalized cost or satisfaction of PT. To do this, many studies use data from hypothetical questions in a contingent valuation framework to estimate time multipliers. To what extent can we confirm these models' findings using a completely different set-up based on linking data from CS with IVD? In our data, CS is measured on an 11-point discrete scale, and we assume there exists a latent continuous variable $C S^{*}$, such that:

$$
C S^{*}=I V D\left(\alpha+\beta_{i} x_{i}\right)+\sum_{k \in K} \gamma_{k} x_{k}+\varepsilon, \forall i \in K
$$

\footnotetext{
${ }^{8}$ Note that this could help justify the interaction effect implicit in the time multiplier studies, in which crowding costs are necessarily increasing in trip duration: productivity losses due to Wasted Time increase in trip duration.

${ }^{9}$ Potential abstract dimensions such as the "lack of control" are hardly quantifiable for users, despite their importance in the psychological literature (see Cox et al., 2006). The interested reader is referred to Mohd Mahudin et al. (2012).
} 
Table 3: Rank and score statistics for the 8 causes of crowding discomfort, $C C D$

\begin{tabular}{llccc}
\hline \hline Category & Cause of dis. & Mean rank & Mean CCD & sd CCD \\
\cline { 1 - 1 } Psychological & Over-closeness & 2.0 & 7.7 & 2.525 \\
\cline { 1 - 1 } Physical & Standing & 3.3 & 6.3 & 3.208 \\
\multirow{2}{*}{ Sensory } & Noise & 4.2 & 5.2 & 2.924 \\
& Smell & 3.1 & 6.6 & 2.827 \\
\multirow{2}{*}{ Temporal } & Time Loss & 4.3 & 5.1 & 2.874 \\
& Waste of Time & 3.9 & 5.5 & 3.116 \\
\multirow{2}{*}{ Risky } & Fall & 5.2 & 3.9 & 6.286 \\
& Robbery & 3.8 & 5.5 & 3.198 \\
\hline \hline
\end{tabular}

Notes. This table reports descriptive statistics for each of the self-reported dissatisfactions with the cause of crowding discomfort, CCD. Column (1) (category) reports the category of the cause of crowding discomfort. Columns (3) reports the reports the mean value of the rank. The rank was obtained by ordering all the dissatisfaction measures for one user. If the two highest dissatisfaction measures are equal, their rank is 1 and the rank of the third highest dissatisfaction mark is 3. Columns (4) and (5) respectively report the mean CCD and the standard deviation of CCD.

where $x$ is a vector individual and trip characteristics and $\varepsilon$ captures the unobservables.

When $\beta_{i}$ is constrained to $0, \alpha$ measures the pure crowding effect on the CS. In order to take into account heterogeneity of the relationship between IVD and CS, we allow for $\beta_{i} \neq 0$, thus including interaction terms between IVD and individual and trip characteristics. We also allow individual and journey characteristics to influence CS independently of IVD.

\subsection{Estimation}

Given the discrete nature of our data on $C S$, we estimate the model using an ordered response model $^{10}$. Ordered choice models allow us to impose only a weak requirement on the interpretation of the scale: All we require is that a user with a $C S$ of 6 is strictly more satisfied than one with a $C S$ of 5 , the difference between a $C S$ of 10 and a $C S$ of 8 may be different from the difference between a $C S$ of 6 and a $C S$ of 4 . Note however that these differences must be homogeneous across different individuals. Table (8) in Appendix "B" also estimates a linear regression model of Equation (1) and finds very similar results.

Column (1) of Table (4) gives results of the restricted specification $\beta_{i}=0$ : As expected, CS decreases

\footnotetext{
${ }^{10}$ We tested both logit and probit frameworks and it made no difference in results. We report probit results.
} 
Table 4: Effects of the density and the income on the comfort satisfaction

\begin{tabular}{|c|c|c|c|c|c|c|}
\hline & \multirow{2}{*}{\multicolumn{2}{|c|}{$\begin{array}{c}(1) \\
\text { CS* }\end{array}$}} & \multirow{2}{*}{\multicolumn{2}{|c|}{$\begin{array}{c}(2) \\
\text { CS* }\end{array}$}} & \multirow{2}{*}{\multicolumn{2}{|c|}{$\begin{array}{c}(3) \\
\text { CS* }\end{array}$}} \\
\hline & & & & & & \\
\hline & Coef. & Std. err. & Coef. & Std. err. & Coef. & Std. err \\
\hline \multicolumn{7}{|l|}{ Crowding effects: } \\
\hline IVD (users $/ \mathrm{m}^{2}$ ) & $-0.550 * * *$ & 0.044 & $0.699 * *$ & 0.334 & $0.651 *$ & 0.349 \\
\hline IVD $\times \ln ($ In. net monthly inc. $)$ & & & $-0.166 * * *$ & 0.043 & $-0.127 * *$ & 0.049 \\
\hline IVD $\times$ Line $(1=$ line $1 / 0=$ line 4$)$ & & & & & -0.072 & 0.086 \\
\hline IVD $\times$ Door to door travel time & & & & & -0.009 & 0.061 \\
\hline IVD $\times$ In-vehicle travel time & & & & & 0.160 & 0.283 \\
\hline IVD $\times$ Peak hour & & & & & -0.065 & 0.066 \\
\hline IVD $\times$ Daily usage & & & & & -0.069 & 0.070 \\
\hline IVD $\times$ Car available & & & & & 0.052 & 0.065 \\
\hline IVD $\times$ Age & & & & & -0.438 & 0.291 \\
\hline IVD $\times$ Gender & & & & & -0.004 & 0.064 \\
\hline \multicolumn{7}{|l|}{ Journey controls: } \\
\hline Line $(1=$ line $1 / 0=$ line 4$)$ & 0.074 & 0.077 & 0.085 & 0.078 & 0.297 & 0.247 \\
\hline Door to door travel time (hours) & 0.070 & 0.052 & 0.065 & 0.051 & 0.094 & 0.196 \\
\hline In-vehicle travel time (hours) & -0.086 & 0.310 & -0.085 & 0.315 & -0.607 & 0.952 \\
\hline Morning Peak dummy & $0.179 * * *$ & 0.067 & $0.184 * * *$ & 0.067 & $0.378 *$ & 0.063 \\
\hline Daily usage of the line $(1=\mathrm{Y} / 0=\mathrm{N})$ & $-0.125 *$ & 0.070 & $-0.127 *$ & 0.070 & 0.092 & 0.214 \\
\hline \multicolumn{7}{|l|}{ Individual controls: } \\
\hline Male & $0.126 *$ & 0.066 & $0.117 *$ & 0.066 & 0.139 & 0.196 \\
\hline Car available & -0.060 & 0.071 & -0.085 & 0.071 & -0.261 & 0.209 \\
\hline ln(Individual net monthly income) & $-0.094 *$ & 0.049 & $0.406 * * *$ & 0.132 & $0.289 *$ & 0.149 \\
\hline Age (centuries) & 0.321 & 0.316 & 0.238 & 0.320 & $1.603 *$ & 0.908 \\
\hline cut1 & -4.139 & 0.335 & -0.459 & 0.979 & -0.602 & 1.016 \\
\hline cut2 & -3.754 & 0.329 & -0.065 & 0.978 & -0.206 & 1.016 \\
\hline cut3 & -3.189 & 0.320 & 0.511 & 0.976 & 0.370 & 1.015 \\
\hline cut 4 & -2.721 & 0.314 & 0.985 & 0.974 & 0.845 & 1.012 \\
\hline $\operatorname{cut} 5$ & -2.306 & 0.312 & 1.405 & 0.974 & 1.265 & 1.012 \\
\hline cut6 & -1.655 & 0.310 & 2.060 & 0.973 & 1.922 & 1.012 \\
\hline cut7 & -1.036 & 0.307 & 2.680 & 0.973 & 2.543 & 1.012 \\
\hline cut8 & -0.414 & 0.304 & 3.303 & 0.971 & 3.169 & 1.012 \\
\hline cut9 & 0.181 & 0.309 & 3.902 & 0.973 & 3.776 & 1.018 \\
\hline cut10 & 0.598 & 0.324 & 4.323 & 0.969 & 4.207 & 1.022 \\
\hline Number of observations & 999 & & 999 & & 999 & \\
\hline Likelihood function & -1953.041 & & -1943.405 & & -1939.915 & \\
\hline Pseudo $\mathrm{R}^{2}$ & 0.086 & & 0.090 & & 0.092 & \\
\hline Prob $>$ chi 2 & 0.000 & & 0.000 & & 0.000 & \\
\hline Akaike IC & 3.950 & & 3.933 & & 3.942 & \\
\hline Number of iterations & 4 & & 4 & & 4 & \\
\hline
\end{tabular}

Notes. This table reports results from ordered probit estimations of Equation (1) when $\beta_{i}=0$ (column (1)), when $x_{i}$ in Eq. (1) is ln (Individual net monthly income (euros)) (column (2)) and with all interaction effects (column (3)). *significant at $10 \% ; *$ significant at $5 \% ; * * *$ significant at $1 \%$. 
with IVD. One additional user per square meter decreases predicted latent $C S^{*}$ by 0.55 (around $3 / 4$ of a standard deviation). Interestingly, the effect appears near-linear: Given our estimates find that a very small variance in the estimated cut-offs for the latent variable $C S^{*}$ (the cut-off distance is around 0.55 points and the s.d. only 0.011), increases in density affect comfort similarly at different points in the density distribution. This regularity in the relationship between density and satisfaction is remarkably consistent with results according to which PT crowding costs grow linearly with IVD (Jara-Díaz and Gschwender, 2003; Wardman and Whelan, 2011; Haywood and Koning, 2015).

Column (3) tests how the crowding effect varies across passengers and trips by including interaction terms. Of all the individual and travel characteristics we test, only income significantly influences the dissatisfaction associated with the IVD ${ }^{11}$. Thus we focus on the estimates in column (2) where we include only the interaction with income. When IVD increases, the satisfaction of wealthier passengers decreases more quickly. To illustrate this result, Figure 2 draws CS as a function of IVD and various levels of income (400, 2,000 and 5,000 euros per month). Other things being equal, wealthier users have a lower CS when vehicles are very crowded (6 users per square meter). Nevertheless, their $C S^{*}$ increases more quickly when IVD decreases.

Importantly, CS does not seem to be driven by the amount of time spent into the vehicles. The in-vehicle travel time coefficient is not significant - neither individually nor as interactions. This raises doubts about the validity of studies that use time multipliers to include crowding cost in PT analyses, e.g. Jara-Díaz and Gschwender (2003); Haywood and Koning (2015); Wardman and Murphy (2015). We are not the first to raise doubts about the time multiplier formulation: Kroes et al. (2013) and de Lapparent and Koning (2015) also find that an additive crowding penalty better fits the data, thus suggesting that PT crowding costs should be specified independently of time costs within the generalized cost function.

Table (4) also reveals that traveling in the morning brings more CS than traveling in the evening. One potential explanation is that these trips often have home as a destination and that users are

\footnotetext{
${ }^{11}$ We also included each of the other variables listed in column (3) sequentially as the only interaction. Only the age variable was significant - but only if we do not include income, indicating that the only significant moderating factor is income. We also tested different functional forms for including income. The Akaike Information Criterion (AIC) confirms that using log income produces the best goodness of fit.
} 


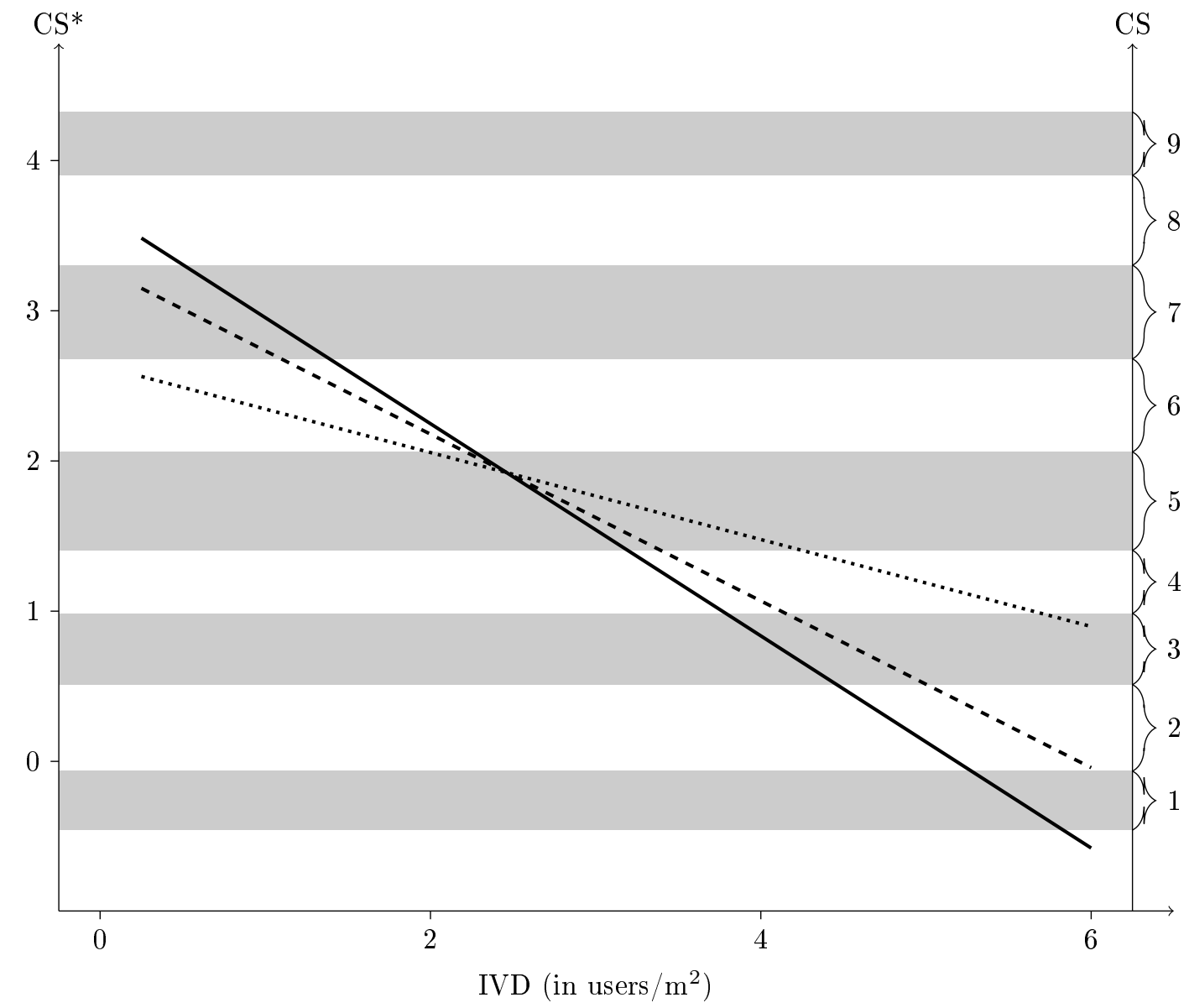

Expected CS* of the representative user with a net monthly income of 400 euros.

- - - Expected CS* of the representative user with a net monthly income of 2,000 euros.

Expected CS* of the representative user with a net monthly income of 5,000 euros.

Figure 2: Latent comfort satisfaction (CS*) and comfort satisfaction (CS) as a function of IVD and income 
more impatient to arrive at home than at other destinations. Maybe tired evening commuters also suffer more from the stress of crowding. We find no "habituation"-effect: To the contrary, frequent passengers tend to be less satisfied by their journey comfort than occasional users. This is in line with Baum and Greenberg (1975) who find that expectations do not reduce people's perception of general level of discomfort. Finally, men are more satisfied with comfort than women. The pseudo- $\mathrm{R}^{2}$ remind us that only a modest share of stated satisfaction measures depends on objective variables (see Kahneman et al., 1999).

\section{Causes of crowding discomfort}

We now address the causes of the crowding effect we found in section " 3 ". Can we identify reasons for the relationship between density and comfort in PT journeys? As potential channels through which IVD may decrease satisfaction we test our eight CCD variables. If cause $d$ is an important channel, we expect the associated interaction effect $\alpha_{d}$ to be significant in Equation $(2)^{12}$.

$$
\begin{aligned}
C S^{*}= & I V D\left(\sum_{d} \alpha_{d} C C D_{d}\right)+\delta \overline{C C D} \\
& +\sum_{k} \gamma_{k} x_{k}+\varepsilon
\end{aligned}
$$

where $\overline{C C D_{i}}=\sum_{d} C C D_{i, d}$ is the sum of $C C D$ rating by an individual $i, x$ is a set of $K$ control variables. ${ }^{13}$ A negative value of $\alpha_{d}$ means that a user who is more dissatisfied by the cause of crowding discomfort $d$ is less tolerant to crowding. $\overline{C C D}$ controls for an individual fixed effect, e.g. some individuals may have a tendency of reporting higher values in all categories due to a different understanding of the scale.

Given that we have information on CCD only for a sub-sample of individuals, we want to control for non-random selection of these individuals. We thus estimate a Heckman selection model ${ }^{14}$. We

\footnotetext{
${ }^{12}$ Note that the causes of discomfort, $C C D_{d}$, are assumed to be cardinal measures of the dissatisfaction. We also need to assume that differences in $C C D_{d}$ across users are stable for all levels of IVD,

${ }^{13}$ The controls are: line, duration of journey, journey time on line, morning peak, daily usage of the line, gender, car ownership, ln (Individual net monthly income (euros)), age and residence in Paris.

${ }^{14}$ The estimate of $\rho$ in Table (5) indicates that there is indeed a selection issue.
} 
require instruments which are correlated with the probability of answering the whole survey, but not correlated with the mark given to $C S$. We rely on two instruments here: The reason for the trip (Motive $1=$ work $/ 0=$ others) and the gender mismatch (a dummy indicating that interviewer and interviewee are not of the same gender). The Motive instrument is chosen because trips related to work are, in average, more time-constrained than others. The surveyed traveler may have chosen not to answer the additional questions because he did not know the duration of these questions. This ensures an informative instrument. Whilst individuals commuting are more time constrained, they appear to be similar along important dimensions - thus we find no significant differences in gender, CS rating, trip duration, car ownership or location of residence. This gives us hope that the instrument is indeed exogenous. The interviewer gender effect on survey participation has been documented in the literature (see Kane and Macaulay, 1993; Catania et al., 1996; Huddy et al., 1997). Whilst the effect may also influence survey responses in some specific cases such as sexual behavior (Catania et al., 1996), gender inequality (Kane and Macaulay, 1993) or feminism and political activism (Huddy et al., 1997), we think that this is unlikely in our survey, which has no obvious gender dimension. There is thus no reason for answers to be influenced by the interviewer gender, suggesting that the instrument is indeed exogenous.

Given the small size of the sub-sample we use a linear regression ${ }^{15}$. The results in Section "3" reassure us that the grid of CS is fine enough so that assuming that CS is a continuous variable does not strongly influence results.

\subsection{Results}

Table (5) reports selected results. Since the main individual and journey effects have been discussed in the previous section, our discussion now focuses on the estimated coefficients of the interaction between IVD and CCD. These are negative and significant for Standing, Over-closeness and Wasted Time. Users who are relatively more dissatisfied by one of these three CCDs perceive a higher disutility of crowding. We therefore consider these as principal channels of the crowding effect.

\footnotetext{
${ }^{15}$ Since there are no thresholds to estimate, we save ten degrees of freedom. The ordered logit IV-regression did not converge.
} 
Table 5: Effect of different causes of crowding discomfort (CCD) on comfort satisfaction (CS)

\begin{tabular}{|c|c|c|}
\hline \multirow[t]{2}{*}{ Main model } & \multicolumn{2}{|c|}{ CS* } \\
\hline & Coef. & Std. err. \\
\hline \multicolumn{3}{|l|}{ Crowding effect: } \\
\hline IVD $\times$ Standing CCD & $-0.033 * * *$ & 0.013 \\
\hline IVD $\times$ Over-closeness CCD & $-0.028 *$ & 0.016 \\
\hline IVD $\times$ Noise CCD & -0.020 & 0.012 \\
\hline IVD $\times$ Robbery CCD & -0.002 & 0.015 \\
\hline IVD $\times$ Fall CCD & 0.012 & 0.014 \\
\hline IVD $\times$ Smell CCD & -0.012 & 0.013 \\
\hline IVD $\times$ Time Loss CCD & -0.022 & 0.014 \\
\hline IVD $\times$ Wasted Time CCD & $-0.030 * *$ & 0.014 \\
\hline Journey characteristics: & \multicolumn{2}{|l|}{$Y$} \\
\hline Individual characteristics: & \multicolumn{2}{|l|}{$Y$} \\
\hline$\sum C C D$ & \multicolumn{2}{|l|}{$0.026 * *$} \\
\hline Constant & \multicolumn{2}{|l|}{$5.085 * * *$} \\
\hline Likelihood function & \multicolumn{2}{|l|}{-1121.009} \\
\hline Wald chi2(18) & \multicolumn{2}{|l|}{225.58} \\
\hline Prob $>\operatorname{chi} 2$ & \multicolumn{2}{|l|}{0.000} \\
\hline Selection model & \multicolumn{2}{|c|}{ sub-sample participation (dummy) } \\
\hline \multicolumn{3}{|l|}{ Excluded Instruments: } \\
\hline Motive $(1=$ work $/ 0=$ other $)$ & -0.140 & 0.091 \\
\hline Gender mismatch (dummy) & $0.152 * *$ & 0.075 \\
\hline \multicolumn{3}{|l|}{ Controls: } \\
\hline Morning peak (dummy) & $-0.469 * * *$ & 0.086 \\
\hline Door to door travel time (hours) & 0.039 & 0.074 \\
\hline Daily usage of the line & $0.170 *$ & 0.095 \\
\hline Age (years) & 0.015 & 0.352 \\
\hline Constant & $-0.492 * * *$ & 0.170 \\
\hline$\rho$ & $0.774 * * *$ & 0.096 \\
\hline \multicolumn{3}{|l|}{ Wald test of indep. eqns. $($ rho $=0)$ : } \\
\hline Prob $>$ chi 2 & \multicolumn{2}{|l|}{0.000} \\
\hline Number of observations & \multicolumn{2}{|l|}{999} \\
\hline Censored observations & \multicolumn{2}{|l|}{721} \\
\hline Uncensored observations & \multicolumn{2}{|l|}{278} \\
\hline
\end{tabular}

Notes. This table reports result estimating Equation (2) taking into account selection. $\rho$ is the estimated correlation between residual of Equation (2), $\varepsilon$, and residuals of the selection quation. Significance levels: * $10 \%$; ** $5 \%$; *** $1 \%$. 
Standing and Wasted Time seem to have the highest impact on CS, followed by Over-closeness. Note that the most important CCDs here follow quite closely the ranking of CCDs in Table (3) with one exception: Whilst Smell is aparently judged an important nuisance in the sample overall, it is ranked highly especially by individuals who are not very sensitive to crowding. In summary, when passenger density is high, users incur a disutility because they have to stand, because they are not able to spend their time usefully and because they suffer from the physical proximity of others.

From a public policy perspective, we can go beyond highlighting the economic costs of PT congestion and thus the benefits of higher service frequency or better rolling stock. Our results suggest that the CS of Paris subway users may be increased by focusing in particular on one of the three channels identified here - Standing, Over-closeness and Wasted Time:

- Reducing the discomfort caused by Standing should not simply consist in adding more seating, since additional seating may generate higher levels of Over-closeness if seats take away room used for standing in crowded conditions. However, it is possible to install fold-up seating that uses very little space in crowded times when individuals must stand.

- Regarding Over-closeness, policy options are limited without changing IVD. The Parisian transport operator is already running ad campaigns exorting passengers to stand up from foldable seats and remove rucksacks from their backs ${ }^{16}$.

- The comfort cost of Wasted Time could be reduced if access to wireless communication (wifi or phone networks) was facilitated.

Finally, PT users do not perceive different causes of discomfort in the same way. Addressing one specific cause of crowding discomfort may favor certain users over others. In order to investigate this issue, Appendix "C" looks at the role of individual characteristics for key CCDs Standing, Wasted Time and Over-closeness. Table (6) summarizes the findings: Women are generally more sensitive to our key CCD causes. Passengers with higher incomes are more likely to suffer from Wasted Time and Over-closeness. Car-owners perceive Wasted Time as a less important feature of

\footnotetext{
${ }^{16}$ See http://www.citylab.com/commute/2012/08/paris-metro-system-forced-admit-parisians-act-jerks/2857/.
} 
Table 6: Main effects of socio-economic variables on different causes of comfort dissatisfaction

\begin{tabular}{lccc}
\hline \hline & Standing & Wasted time & Over-clos. \\
\hline Male & $(-)$ & $(-)$ & $(-)$ \\
Income & & $(+)$ & $(+)$ \\
Age & & $(-)$ & \\
Car available $(1=\mathrm{Y})$ & & $(-)$ & \\
\hline
\end{tabular}

Notes. The signs displayed in this table are the signs of significant coefficients obtained through regressing $\mathrm{CCD}$ ratings on these individual characteristics (controlling for selection). Table (9) in Appendix " $\mathrm{C}$ " provides all results.

Reading: (+) means that a policy addressing this cause of crowding discomfort would increase more the CS of users with these characteristics. (-) means that a policy addressing this cause would increase less the CS of users with these characteristics.

crowding, maybe because they know that they can occupy their travel time in a better way than if they had to focus on the road traffic, whatever the level of density. Alternately, individuals who enjoy working and reading during transport (and hence are very sensitive to Wasted Time) do not own a car. Finally, old people tend to be less affected by this nuisance.

\section{Conclusion}

A growing body of research focuses on the cost of PT crowding in terms of passenger welfare. This paper has used an survey on stated satisfaction collected on Paris subway platforms to investigate this crowding effect. We add evidence from an interesting new type of data to a literature that has mostly focused on contingent valuation. Our analysis includes an original discussion on the causes of the crowding effect. Our main conclusions can be summarized as follows: First, our results suggest that crowding costs cannot be modeled as a time multiplier, the most common assumption in contingent valuation studies. Rather, crowding costs enter additively in the generalized PT cost function. Second, we confirm previous findings that crowding costs grow linearly with IVD. Third, wealthier users' satisfaction decreases more quickly with IVD; Fourth, we identify three causes of dissatisfaction with crowding: a higher probability to stand for all or part of the journey, a poorer use of the time during the journey, and a shorter average distance from other users during the journey; Finally, women and wealthy individuals are more likely to benefit from any policy addressing one or more of these three channels. 


\section{References}

Baum, A., Greenberg, C. I., 1975. Waiting for a crowd: The behavioral and perceptual effects of anticipated crowding. Journal of personality and social psychology 32 (4), 671.

Bhattacharya, S. K., Bandyopadhyay, P., Kashyap, S. K., 1995. Calcutta metro: is it safe from noise pollution hazards? Industrial health 34 (1), 45-50.

Boussenna, M., Corlett, E., Pheasant, S., 1982. The relation between discomfort and postural loading at the joints. Ergonomics 25 (4), 315-322.

Cantwell, M., Caulfield, B., O'Mahony, M., 2009. Examining the factors that impact public transport commuting satisfaction. Journal of Public Transportation 12 (2), 1-21.

Catania, J. A., Binson, D., Canchola, J., Pollack, L. M., Hauck, W., Coates, T. J., 1996. Effects of interviewer gender, interviewer choice, and item wording on responses to questions concerning sexual behavior. Public Opinion Quarterly 60 (3), 345-375.

Clark, A. E., Senik, C., 2010. Who compares to whom? the anatomy of income comparisons in europe. The Economic Journal 120 (544), 573-594.

Cox, T., Houdmont, J., Griffiths, A., 2006. Rail passenger crowding, stress, health and safety in britain. Transportation Research Part A: Policy and Practice 40 (3), 244-258.

De Borger, B., Wouters, S., 1998. Transport externalities and optimal pricing and supply decisions in urban transportation: a simulation analysis for belgium. Regional Science and Urban Economics $28(2), 163-197$.

de Lapparent, M., Koning, M., 2015. Analyzing time sensitivity to discomfort in the paris subway: an interval data model approach. Transportation, 1-21.

de Palma, A., Kilani, M., Proost, S., 2015. Discomfort in mass transit and its implication for scheduling and pricing. Transportation Research Part B: Methodological 71 (0), 1-18.

Dell'Olio, L., Ibeas, A., Cecin, P., 2011. The quality of service desired by public transport users. Transport Policy 18 (1), 217-227. 
Eboli, L., Mazzulla, G., 2007. Service quality attributes affecting customer satisfaction for bus transit. Journal of Public Transportation 10 (3), 21.

Epstein, Y. M., 1981. Crowding stress and human behavior. Journal of Social Issues 37 (1), 126-144.

Epstein, Y. M., Teitelbaum, R., Karlin, R. A., Katz, S., Aiello, J. R., 1981. An assessment of the effectiveness of two tactics to reduce arousal in crowded mass transit settings1. Journal of Applied Social Psychology 11 (3), 259-267.

Haywood, L., Koning, M., 2015. The distribution of crowding costs in public transport: New evidence from paris. Transportation Research Part A: Policy and Practice 77, 182-201.

Henderson, J., 1981. The economics of staggered work hours. Journal of Urban Economics 9 (3), $349-364$.

Huddy, L., Billig, J., Bracciodieta, J., Hoeffler, L., Moynihan, P., Pugliani, P., 1997. The effect of interviewer gender on the survey response. Political Behavior 19 (3), 197-220.

Jara-Díaz, S. R., Gschwender, A., 2003. Towards a general microeconomic model for the operation of public transport. Transport Reviews 23 (4), 453-469.

Kahneman, D., Diener, E., Schwarz, N., 1999. Well-being: Foundations of hedonic psychology. Russell Sage Foundation.

Kahneman, D., Krueger, A. B., 2006. Developments in the measurement of subjective well-being. The journal of economic perspectives 20 (1), 3-24.

Kane, E. W., Macaulay, L. J., 1993. Interviewer gender and gender attitudes. Public Opinion Quarterly $57(1), 1-28$.

Kraus, M., 1991. Discomfort externalities and marginal cost transit fares. Journal of Urban Economics $29(2), 249-259$.

Kroes, E., Kouwenhoven, M., Debrincat, L., Pauget, N., 2013. On the value of crowding in public transport for île-de-france. International Transport Forum Discussion Paper. 
Langrehr, F. W., 1991. Retail shopping mall semiotics and hedonic consumption. Advances in Consumer Research 18 (1), 428-433.

Li, Z., Hensher, D. A., 2011. Crowding and public transport: A review of willingness to pay evidence and its relevance in project appraisal. Transport Policy 18 (6), 880-887.

Metcalfe, R., Dolan, P., 2012. Behavioural economics and its implications for transport. Journal of Transport Geography 24, 503-511.

Meyers-Levy, J., Maheswaran, D., 1991. Exploring differences in males' and females' processing strategies. Journal of Consumer Research, 63-70.

Meyers-Levy, J., Sternthal, B., 1991. Gender differences in the use of message cues and judgments. Journal of marketing research, 84-96.

Mohd Mahudin, N. D., Cox, T., Griffiths, A., 2012. Measuring rail passenger crowding: Scale development and psychometric properties. Transportation research part F: traffic psychology and behaviour $15(1), 38-51$.

Parry, I. W., Small, K. A., 2009. Should urban transit subsidies be reduced? American Economic Review 99 (3), 700-724.

Small, K. A., Verhoef, E. T., 2007. The economics of urban transportation. Routledge.

Stokols, D., 1972. On the distinction between density and crowding: Some implications for future research. Psychological review $79(3), 275$.

Tirachini, A., Hensher, D. A., Rose, J. M., 2013. Crowding in public transport systems: effects on users, operation and implications for the estimation of demand. Transportation research part A: policy and practice $53,36-52$.

Uzzell, D., Brown, J., 2007. Conceptual progress in understanding fear of crime in railway stations. Psicologia 21 (2), 119-137.

Van Praag, B. M., Ferrer-i Carbonell, A., 2008. Happiness quantified: A satisfaction calculus approach. Oxford University Press. 
Wardman, M., Murphy, P., 2015. Passengers' valuations of train seating layout, position and occupancy. Transportation Research Part A: Policy and Practice 74, 222-238.

Wardman, M., Whelan, G., 2011. Twenty years of rail crowding valuation studies: evidence and lessons from british experience. Transport Reviews 31 (3), 379-398.

\section{Appendices}

\section{A Representativeness of the sample}

The sample consists of 999 passengers, the sub-sample contains 278 interviewees. Table (7) contrasts our sample to a representative sample of the overall peak hour subway user population taken from from the "Enquête Globale Transport" (EGT) ${ }^{17}$. The EGT survey is conducted every ten years by the PT regulator in the Ile-de-France region. 18,000 households are surveyed and weighted to ensure sample representativeness at the regional scale. When compared with the EGT sample, our sample is on average more manly, younger, less likely to live in central Paris, poorer and more likely to own a car. Despite this, we find that our sample is fairly representative.

\section{B Crowding effect estimation using OLS}

Table (8) shows results using a linear specification of the crowding effect, i.e. estimating Equation (1) using OLS.

\section{Users preferences for the nuisance factors}

Sub-sample respondents rate their level of dissatisfaction about the causes of discomfort assuming that the IVD is the highest, i.e 6 users per square meter. We wish to test whether socioeconomic

\footnotetext{
${ }^{17}$ Peak hours are here defined as the 7:30-10 am and 5-7:30pm periods.
} 
Table 7: Individual and journey characteristics for the whole sample, the sub-sample and the EnquÃ ${ }^{a}$ te Globale Transport (EGT)

\begin{tabular}{|c|c|c|c|c|c|}
\hline & & Sample & Sub-sample & Diff. sign. & EGT Sample \\
\hline$N$ & & 999 & 278 & & 2,414 \\
\hline Female (\%) & & 51.5 & 52.6 & n.s. & 55.1 \\
\hline Age (Years) & & $\begin{array}{c}35.8 \\
(\mathrm{sd}: 12.4)\end{array}$ & $\begin{array}{c}35.5 \\
(\mathrm{sd}: 13.4)\end{array}$ & n.s. & $\begin{array}{c}38.1 \\
(\mathrm{sd}: 14.4)\end{array}$ \\
\hline Car available (\%) & & 37.4 & 36.4 & n.s. & 33.5 \\
\hline Income (Euros) & & $\begin{array}{c}2,422 \\
(\mathrm{sd}: 2,293)\end{array}$ & $\begin{array}{c}2,282 \\
(\mathrm{sd}: 2,126)\end{array}$ & n.s. & $\begin{array}{c}2,321 \\
(\mathrm{sd}: 1,861)\end{array}$ \\
\hline Live in Paris $(\%)$ & & 52.7 & 44.5 & n.s. & 61.6 \\
\hline Interviewed during morning peak (\%) & & 50 & 36 & $* * *$ & - \\
\hline Interviewed during evening peak (\%) & & 50 & 64 & $* * *$ & - \\
\hline \multirow[t]{2}{*}{ Motive (\%) } & Work & 70.2 & 66 & $*$ & 56 \\
\hline & Other & 29.8 & 34 & $*$ & 44 \\
\hline \multirow[t]{2}{*}{ Line $(\%)$} & Line 1 & 50.1 & 55.1 & $* *$ & - \\
\hline & Line 4 & 49.9 & 44.9 & $* *$ & - \\
\hline \multirow{2}{*}{\multicolumn{2}{|c|}{ Total travel time (minutes) }} & 48.1 & 46.9 & n.s. & 41.5 \\
\hline & & (sd: 36.7$)$ & (sd: 35.4$)$ & & - \\
\hline \multirow{2}{*}{\multicolumn{2}{|c|}{ Surveyed travel time (minutes) }} & 9.7 & 9.6 & n.s. & - \\
\hline & & (sd: 6.5$)$ & (sd: 6.25) & & - \\
\hline \multirow{3}{*}{\multicolumn{2}{|c|}{$\begin{array}{l}\text { Daily use of the line (\%) } \\
\text { In-vehicle density (users } / \mathrm{m}^{2} \text { ) }\end{array}$}} & 63.3 & 66.9 & n.s. & - \\
\hline & & 3.153 & 3.232 & n.s. & - \\
\hline & & (sd: 1.203) & (sd: 1.191) & & - \\
\hline \multicolumn{2}{|l|}{ Comfort satisfaction $(0-10)$} & $\begin{array}{c}4.464 \\
\text { (sd: } 2.186)\end{array}$ & $\begin{array}{c}4.230 \\
(\mathrm{sd}: 2.218)\end{array}$ & $* *$ & \\
\hline
\end{tabular}

Notes. This table summarizes a specialized survey collected in the Parisian subway and the EGT sample of users using the Paris subway during peak periods. Percentages denote frequencies. Age and income means and standard developments are computed with the center of the categories. Significance levels: *** (1\%), $* *(5 \%)$, and *(10\%), using a two sided t-test comparing variable means of sample and subsample. 


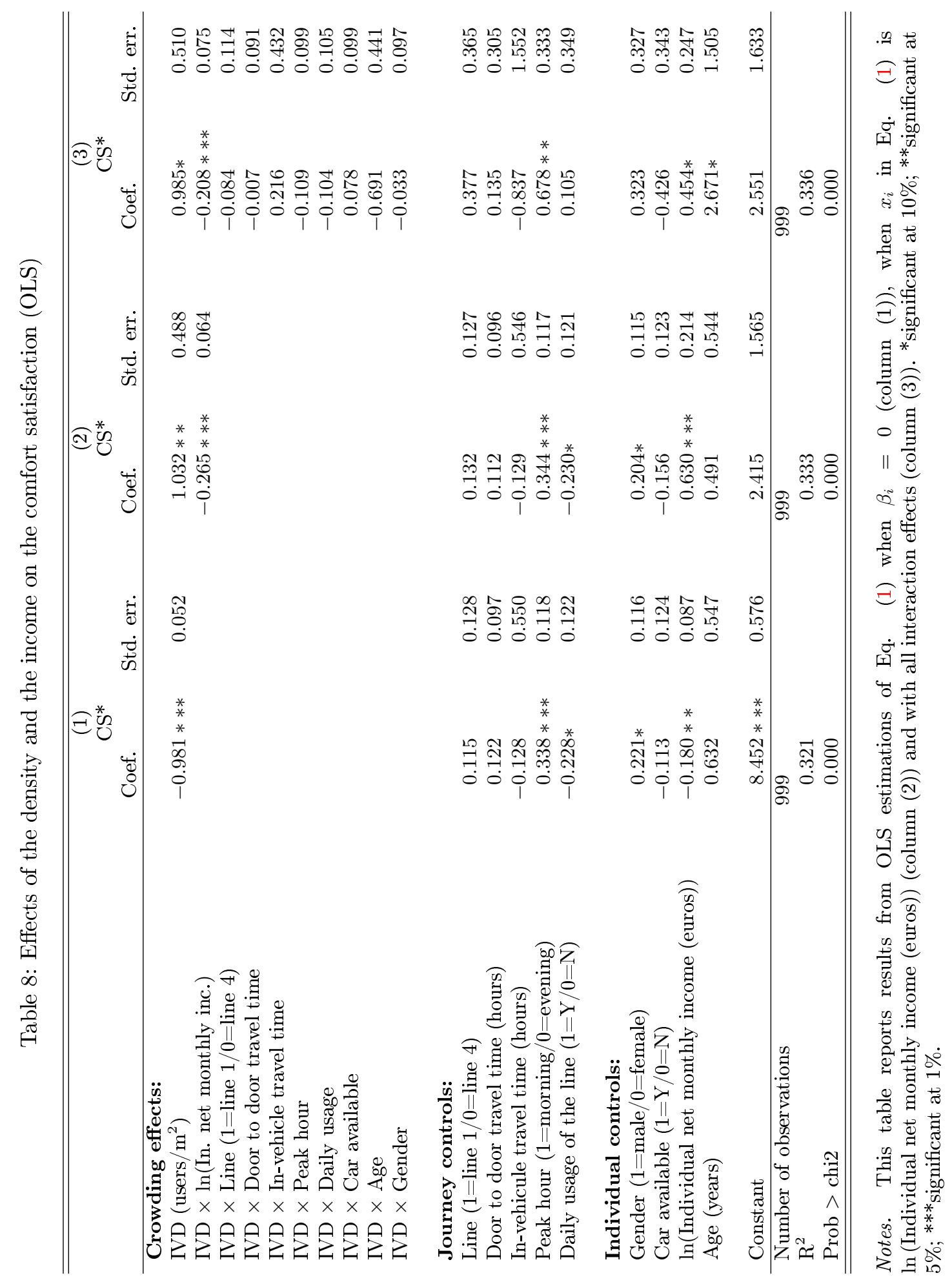


variables drive these self-reported marks. We therefore estimate the following equation:

$$
C C D_{d}^{*}=\beta_{1 d} X+\beta_{2 d} Z+\varepsilon_{d}
$$

where CCD is the latent variable associated with the dissatisfaction mark given to the cause of discomfort $d . X$ is a set of individual characteristics: gender (dummy), car availability (dummy), $\ln$ (Individual net monthly income (euros)), age (centuries) and live in Paris (dummy). It is conceivable that answers are affected by the current journey of users. To control for these effects, we also include a characteristics of the journey, $Z$ : line where the user is surveyed (dummy) and the immediate journey travel time (hours).

We control the selection bias with the Heckman selection model. Reported ratings for different CCD are assumed to be cardinal measures of dissatisfaction. We focus on the causes which we have found to influence comfort dissatisfaction most strongly, i.e. Standing, Wasted Time and Over-closeness. Tables (9) reports results from estimating Equation (3) using a Heckman selection model (specified as above). First, there is a clear gender effect: men are a lot less dissatisfied than women by the three nuisance factors. This is in line Meyers-Levy and Maheswaran (1991) and Meyers-Levy and Sternthal (1991) who find that women process information in more detail, resulting in a greater sensitivity to environmental factors. Second, wealthier users are more affected by Wasted Time andOver-closeness. This effect is not surprising and corresponds to results found in Section " 3 ". It may be consistent with their higher value of time. Third, car ownership influences the perception of crowding nuisances. Car-owner users seem to compare the crowding conditions in PT with the individual car travel conditions. As a consequence, they find the Wasted Time less penalizing than other users do, maybe because they know that they can occupy their travel time in a better way than if they had to focus on the road traffic, whatever the level of density. Finally, a negative age effect is perceptible for Wasted Time. 


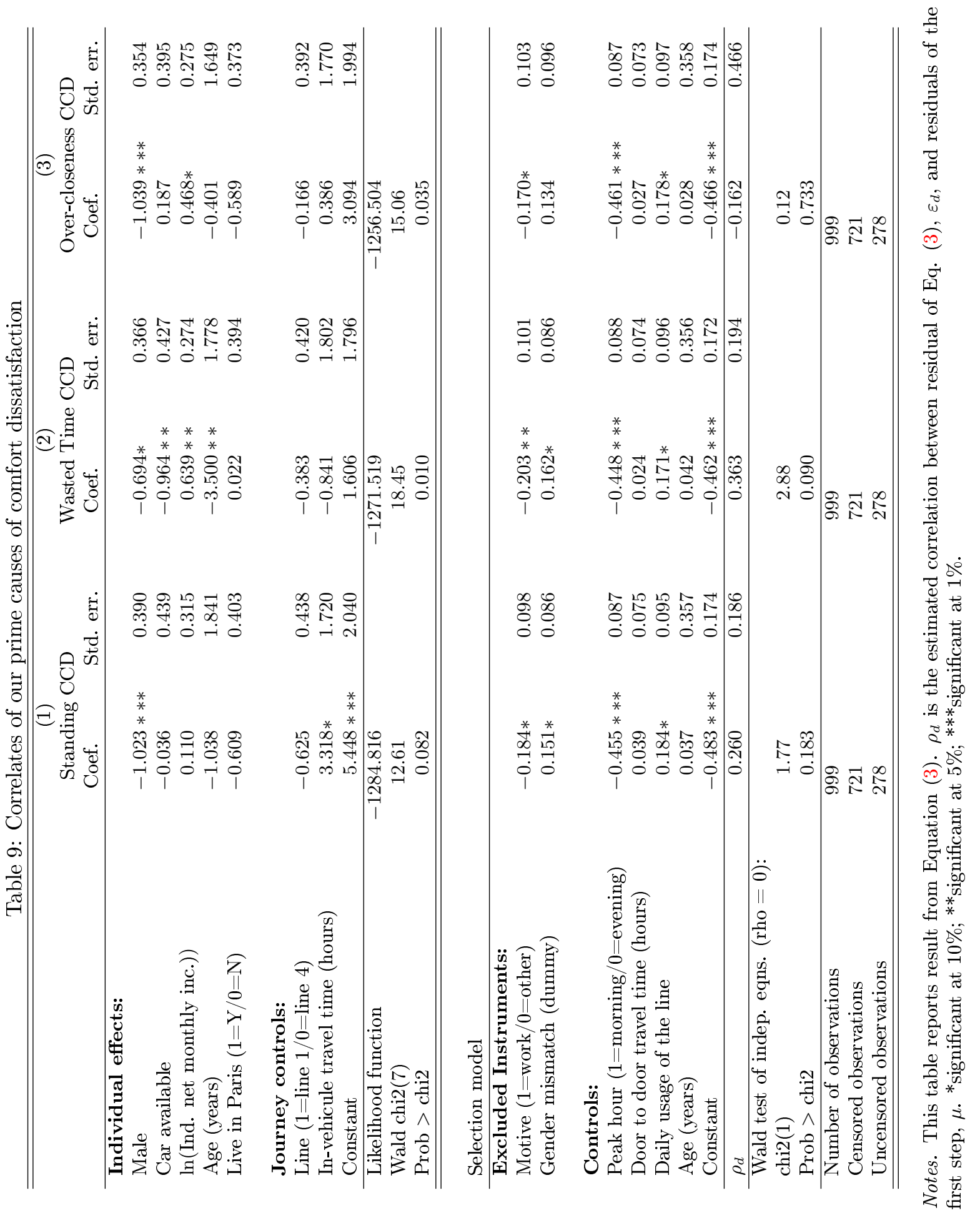

